\title{
Pneumonia of Children under 5 Years of Age in Brazzaville (Republic of Congo)
}

\author{
A. R. Okoko1,2, E. Hossie'2, I. C. N'djobo-Mamadoud1, E. Moyen',2, \\ G. Ekouya Bowassa ${ }^{1,2}$, G. Moyen ${ }^{1,2}$ \\ ${ }^{1}$ Department of Pediatrics, University Hospital of Brazzaville, Brazzaville, Congo \\ ${ }^{2}$ Department of Doctoral Studies, Faculty of Health Sciences, Marien Ngouabi University of Brazzaville, Brazzaville, Congo \\ Email: okoko_annie@yahoo.fr
}

How to cite this paper: Okoko, A.R., Hossie, E., N'djobo-Mamadoud, I.C., Moyen, E., Ekouya Bowassa, G. and Moyen, G. (2017) Pneumonia of Children under 5 Years of Age in Brazzaville (Republic of Congo). Open Journal of Pediatrics, 7, 178-191. https://doi.org/10.4236/ojped.2017.73021

Received: August 4, 2017

Accepted: September 4, 2017

Published: September 7, 2017

Copyright (c) 2017 by authors and Scientific Research Publishing Inc. This work is licensed under the Creative Commons Attribution International License (CC BY 4.0).

http://creativecommons.org/licenses/by/4.0/ (c) (i) Open Access

\begin{abstract}
Pneumonia is one of the prime causes of morbidity and mortality in children under five years of age. Objectives: To determine the frequency of pneumonia, to identify the causative organisms and the factors associated with death in children under 5 years of age. Methods: A prospective cohort study was performed in children 1 to 59 months hospitalized for pneumonia between January and June 2016 in CHUB pediatric wards. Results: A total of 237 children were hospitalized for pneumonia, i.e. $12.3 \%$ of hospitalizations. There were 133 boys (56\%) and 104 girls (44\%) with a mean age of $15.9 \pm 13.8$ months. The average time elapsed between onset of symptoms and hospitalization was $7.2 \pm 6.1$ days. The alveolar syndrome 185 cases $(81 \%)$, alveolo-interstitial 34 cases (15\%), alveolar and pleural 9 cases (4\%) were the main radiological translations. Blood cultures were positive in 74 cases (31\%) and the bacteria identified were: Streptococcus pneumoniae 42 cases (17.5\%), Staphylococcus Aureus 23 cases (9.6\%) and Klebsiella pneumoniae 9 cases (3.7\%). HIV serology was positive in 19 cases (8\%). Fifty-eight (58) children (24\%) died. Factors associated with death were respiratory distress, hypoxemia and hypothermia. Conclusion: Pneumonia of children under 5 years of age is frequent and severe prognosis. Their mastery requires the strengthening of the national respiratory disease control program and the knowledge of risk factors.
\end{abstract}

\section{Keywords}

Pneumonia, Children, Morbidity, Mortality, Risk Factors, Brazzaville, Congo

\section{Introduction}

Pneumonia is a major cause of morbidity and mortality in children under five 
years of age [1]. By 2015, 5.9 million children under five years of age have died from pneumonia, including 70\% in sub-Saharan Africa and Southeast Asia [1] [2] [3] [4]. In Africa, pneumonia accounts for $25 \%$ - 33\% of hospitalizations [5] [6] [7]. HIV/AIDS infection has increased its morbidity due to the well-established relationship between pneumonia and HIV infection [8].

Pneumonia can be prevented by vaccination and its mortality reduced with the implementation of the WHO strategy [1] for the management of Acute Respiratory Infections (ARI) in children under five years of age. This is based on early clinical screening and rational use of antibiotic therapy in primary and peripheral hospitals.

In the Congo, the prevalence of pneumonia is not known, nor there is a system for the epidemiological surveillance of respiratory diseases in children. However, respiratory emergencies are the second leading cause of hospitalization in children under 5 years of age, according to the study by Moyen et al. [9].

This first Congolese study aimed to determine the frequency of pneumonia and to identify the causative germs and factors associated with death in children under 5 years of age in Brazzaville.

\section{Methodology}

This was a prospective cohort study conducted between January and June 2016 at the University Hospital of Brazzaville (UHB) in the Republic of Congo. The population of Brazzaville was estimated at 1,373,382 inhabitants in 2015, the climate is tropical with an average annual temperature of $25.5^{\circ} \mathrm{C}$.

Children aged 1 to 59 months admitted to the pediatric wards during the study period, meeting the diagnostic criteria for pneumonia, were included. Parental consent was required and obtained to be eligible. The diagnostic criteria of the pneumonia selected were those defined by the WHO [10]: pneumonia is said to have no sign of severity when breathing is rapid ( $\geq 60$ cycles per minute in children less than 2 months, $\geq 50$ cycles per minute between 2 and 11 months and $\geq 40$ cycles per minute between 1 and 5 years) associated with crackling rats on auscultation. Pneumonia is said to be severe when, at the signs of pneumonia without signs of gravity, a draw is associated. Pneumonia is said to be very severe when severe pneumonia is associated with central cyanosis, inability to drink or nurse, incoercible vomiting, convulsions, lethargy or loss of consciousness, severe respiratory distress.

Children with chronic cough were not included in the haunting of tuberculosis.

The variables analyzed were:

$>$ Epidemiological:

- Those related to parents: age, educational level, socio-economic level, number of adults sleeping in the same room as children under 5 years of age, use of oil lamp for lighting houses, fumigant tortillons used for mosquito control, parental smoking; 
- Child related: age in months, sex, consultation time, antibiotics received prior to hospitalization, vaccination status for pneumococcal antigens and Haemophilus influenzae b, feeding for the first six months, the existence of a particular terrain such as HIV/AIDS, sickle cell disease, heart disease, diabetes.

Clinic:

The state of consciousness, temperature, color, respiratory rate, moisture state, nutritional status, signs of pulmonary auscultation, percutaneous oxygen saturation and the existence of hepatomegaly and/or splenomegaly.

Paraclinic:

The radiograph of the thorax, interpreted by two paediatricians, with confirmation in each case by a radiologist, a hemogram, C-reactive protein, retroviral serology (HIV) and blood culture whose technique was as follows: After sampling of blood on culture medium, an incubation in the oven at $37^{\circ} \mathrm{C}$. In the BacT-Alert 3D automaton was carried out for five days. Beyond that, the bacteria detected were contaminants. The inoculum was seeded in the following culture media: cooked blood agar supplemented with poly vitex for the growth of Streptococcus pneumoniae and Haemophilus Influenzae, fresh (human) blood culture agar for streptococcus culture, Chapman medium for culture of staphylococci. Microscopic analysis was performed using Gram staining, identification and antibiogram were performed by the Compact 2 raptor. Quality control was performed using the reference strains recommended by CA-SFM/EUCAST for: Streptococcus pneumoniae ATCC 49616, Staphylococcus aureus ATCC 29213 and Klebsiella pneumoniae ATCC 700603.

Therapeutic and Evolutionary

Treatment during hospitalization, length of hospital stays, observed complications, and type of progression (favorable outcome, progression to death or complications).

\subsection{Definitions of Concepts}

- The socio-economic level was assessed on the basis of the food poverty line defined by the National Congolese Center for Statistics and Economic Studies (CNSEE) [11]: it is said to be low when the family spends less than 523 FCFA (African Financial Community Franc/CFA. 1 Dollar $=550$ CFA Francs $=)$ per person per day, average between 523 and 1685 CFA francs and raised between 1685 and 5055 CFA francs.

- Hypoxemia was retained when the oxygen saturation was less than $90 \%$.

- Nutritional status was assessed on the basis of WHO growth standards [12].

- The typology of the radiological images was made by referring to the WHO standardized criteria [13].

- For HIV serology, presumptive diagnosis in infants under 18 months of age was retained when the infant met the following criteria: signs suggestive of HIV infection [14], the positivity of its serology and that of his mother 
[14].

- The cough was called chronic for a duration greater than or equal to 1 month.

- Vaccination was up-to-date when the child received 3 doses of both vaccine serotypes (PCV13 and HI b).

- Polypnea was defined as fast breathing ( $\geq 60$ cycles per minute in children less than 2 months of age, $\geq 50$ cycles per minute between 2 and 11 months and $\geq 40$ cycles per minute between 1 and 5 years of age.

- Hypothermia was defined as a temperature below $35^{\circ} \mathrm{C}$.

- Promiscuity has been defined by the existence of more than three persons other than the child under 5 years of age.

\subsection{Ethical Considerations}

The study protocol obtained the approval of the Committee of Ethics of Health Sciences Research: N 041/MRSIT/IRSSA/CERSSA.

\subsection{Statistical Analysis}

Data was entered using CS Pro and SPSS ${ }^{\circledR} 16$. Percentages, averages and standard deviations were calculated. In order to assess the influence of age on certain variables and to identify the determinants of pneumonia-related mortality, an analytical study was carried out with relative risk (RR) and confidence interval (CI) to $95 \%$. In order to identify the factors associated with mortality, some variables were adjusted on others to eliminate the confounding factors, thus allowing the calculation of the adjusted $R R$ * by the Logit method. The statistical influence observed between two variables was assessed by the Pearson chi-square test, the significance level of the comparisons was $<0.05$.

\section{Results}

\section{1) Sociodemographic characteristics of parents (Table 1)}

\section{2) Epidemiological Aspects}

\section{- Frequency, age and sex}

During the study period, 1934 children under 5 years were hospitalized, 237 of whom were pneumonia (12.3\%). Pneumonia was the third leading cause of hospitalization after malaria and bronchiolitis. There were 133 boys (56\%) and 104 girls (44\%), with an average of $15.9 \pm 13.8$ months extremes (1 and 59 months).

\section{- Type of breastfeeding, vaccination profile and field}

Exclusive breastfeeding during the first six months of life was performed in 112 children (47.3\%), pneumococcal vaccination (PCV13) and anti-Haemophilus influenzae b in $191(80.6 \%)$ and $303(85,6 \%)$ children. There were $15(6.3 \%)$ children born prematurely, 13 (5.5\%) sickle-cell anemia and 11 (4.6\%) with congenital heart disease.

- Living conditions of children: living conditions are recorded in Table 2. 
Table 1. Sociodemographic characteristics of parents.

\begin{tabular}{|c|c|c|c|c|}
\hline & \multicolumn{2}{|c|}{ Father } & \multicolumn{2}{|c|}{ Mother } \\
\hline & $\mathrm{N}$ & $\%$ & $\mathrm{~N}$ & $\%$ \\
\hline \multicolumn{5}{|l|}{ Age range } \\
\hline$<20$ & 0 & 0.0 & 9 & 3.8 \\
\hline $20-34$ & 120 & 50.6 & 172 & 72.6 \\
\hline$\geq 35$ & 117 & 49.4 & 56 & 23.6 \\
\hline \multicolumn{5}{|l|}{ Level of education } \\
\hline Unschooled & 7 & 3.0 & 5 & 2.1 \\
\hline Primary & 85 & 35.9 & 93 & 39.2 \\
\hline Secondary & 107 & 45.1 & 114 & 48.2 \\
\hline Superior & 38 & 16.0 & 25 & 10.5 \\
\hline \multicolumn{5}{|l|}{ Professional situation } \\
\hline Senior & 16 & 6.8 & 9 & 3.8 \\
\hline Middle management & 40 & 16.9 & 22 & 9.3 \\
\hline Qualified worker & 127 & 53.6 & 24 & 10.1 \\
\hline Maneuver & 1 & 0.4 & 21 & 8.9 \\
\hline Self-employed worker & 14 & 5.9 & 47 & 19.8 \\
\hline High & 2 & 0.8 & 14 & 5.9 \\
\hline Student & 2 & 0.8 & 8 & 3.4 \\
\hline Unemployed & 35 & 14.8 & 92 & 38.8 \\
\hline \multicolumn{5}{|l|}{ Socio-economic level } \\
\hline Low & 171 & 72.2 & 189 & 79.7 \\
\hline Middle & 63 & 26.6 & 45 & 19.0 \\
\hline High & 3 & 1.3 & 3 & 1.3 \\
\hline \multicolumn{5}{|l|}{ Smoking } \\
\hline Yes & 22 & 9.3 & 3 & 1.3 \\
\hline No & 215 & 90.7 & 234 & 98.7 \\
\hline Total & 237 & 100 & 237 & 100 \\
\hline
\end{tabular}

\section{- Antibiotic treatment received before hospitalization and consultation period}

An antibiotic was administered before hospitalization in 105 (44\%) children, by the mother 95 (90\%) children and by a health worker 10 (10\%) children. The average time elapsed between the onset of symptoms and the day of hospitalization was $7.2 \pm 6.1$ days.

\section{3) Clinical Aspects}

Nutritional status was normal in 179 children (75.5\%), wasting was observed in 37 children (15.6\%) and severe wasting in 21 children (8.9\%). 
Table 2. Distribution of children according to living conditions.

\begin{tabular}{|c|c|c|}
\hline & $\mathbf{N}$ & $\%$ \\
\hline \multicolumn{3}{|l|}{ Household size } \\
\hline Number of persons $<5$ & 114 & 48.1 \\
\hline Number of persons $\geq 5$ & 123 & 51.9 \\
\hline \multicolumn{3}{|c|}{ Number of children in the family } \\
\hline Number of children $<5$ & 185 & 78.1 \\
\hline Number of children $\geq 5$ & 52 & 21.9 \\
\hline \multicolumn{3}{|l|}{ Number of rooms } \\
\hline Number of room $\leq 2$ & 217 & 91.6 \\
\hline Number of room $>2$ & 20 & 8.4 \\
\hline \multicolumn{3}{|l|}{ Number of people per room } \\
\hline Number of persons $\leq 2$ & 36 & 15.2 \\
\hline Number of persons $>2$ & 201 & 84.8 \\
\hline \multicolumn{3}{|c|}{ Number of adults sharing the same } \\
\hline \multicolumn{3}{|c|}{ room than the child under 5 years old } \\
\hline Number of adults $<2$ & 103 & 43.5 \\
\hline Number of adults $\geq 2$ & 134 & 56.5 \\
\hline \multicolumn{3}{|l|}{ Smokers in the house } \\
\hline Yes & 25 & 10.5 \\
\hline No & 212 & 89.5 \\
\hline \multicolumn{3}{|l|}{ Use of oil lamp } \\
\hline Yes & 113 & 47.7 \\
\hline No & 124 & 52.3 \\
\hline \multicolumn{3}{|l|}{ Use of smoke twists } \\
\hline Yes & 35 & 14.8 \\
\hline No & 202 & 85.2 \\
\hline
\end{tabular}

The signs of examination are given in Table 3, the classification of pneumonia according to the stage of severity, and the age and severity of pneumonia in $\mathrm{Ta}$ ble 4.

\section{4) Paraclinical Aspects}

\section{- Pulmonary radiography}

Opacity in focus was observed in 228 children (96.2\%). It was unilateral in 146 children (64.2\%) and bilateral in 82 children (35.8\%). Lower lobe involvement was observed in 73 children (32.0\%), the average lobe in 48 children (21\%), the upper lobe in 39 children (17\%) and hemi thorax in 68 children (30\%). These opacities were subdivided into alveolar syndromes in 185 children (81\%), alveolo-interstitial in 34 children (15\%) and alveolar with pleural effusion in 9 children $(4 \%)$. 
Table 3. Signs of examination.

\begin{tabular}{ccc}
\hline Signs & N & $\%$ \\
\hline Fever $^{*}$ & 226 & 95.4 \\
Difficulty breathing* & 147 & 62 \\
Cough & 96 & 55 \\
Crackling Rails & 222 & 93.7 \\
Coma & 24 & 10 \\
Pallor & 23 & 9.7 \\
Hepatomegaly & 20 & 8.4 \\
Diarrhea & 10 & 4.2 \\
Convulsions & 9 & 3.8 \\
Sp $\mathrm{O}_{2}<96 \% * * *$ & 133 & 56 \\
\hline
\end{tabular}

${ }^{*}$ The mean axillary temperature was $38.3^{\circ} \mathrm{C}$ (extremes: $35.8^{\circ} \mathrm{C}$ and $40.5^{\circ} \mathrm{C}$ ). ${ }^{*}$ The mean respiratory rate was 60 cycles per minute (extremes: 40 and 76 cycles per minute). ${ }^{* * *}$ The average partial saturation of oxygen was $93 \%$ (extremes: $40 \%$ and $100 \%$ ).

Table 4. Relationship between age and severity of pneumonia.

\begin{tabular}{ccccc}
\hline & $\begin{array}{c}\text { Children }<24 \\
\text { months }\end{array}$ & $\begin{array}{c}\text { Children } \geq 24 \\
\text { months }\end{array}$ & RR95\% & $\boldsymbol{P}$ \\
\hline Pneumonia without severity & 79 & 25 & $0.9[0.8-1.1]$ & 0.7 \\
Severe pneumonia & 64 & 25 & $0.9[0.7-1.0]$ & 0.1 \\
Very severe pneumonia & 39 & 5 & $1.1[1.0-1.3]$ & 0.03 \\
\hline
\end{tabular}

Very severe pneumonia is significantly more prevalent in infants younger than 24 months $(P=0.03)$.

\section{- Biological examinations}

Leukocytosis was noted in 186 cases (78.5\%), an average hemoglobin level of $9.5 \mathrm{~g} / \mathrm{dl} \pm 2.05$ extremes ( 4.5 and $12.5 \mathrm{~g} / \mathrm{dl}$ ), and C-Reactive Protein was greater than $20 \mathrm{mg} / \mathrm{l}$ in all cases.

Retroviral serology was positive in 19 cases (8\%) and positive blood culture in 74 cases (31\%). The organisms identified were Streptococcus pneumoniae 42 cases (17.5\%), Staphylococcus aureus 23 cases (9.6\%) and Klebsiella pneumoniae 9 cases $(3.7 \%)$.

\section{5) Treatment-Evolution}

Antibiotic treatment was administered parenterally in 187 cases (78.9\%) and orally in 50 cases $(21.1 \%)$. The antibiotics administered were a cephalosporin of 3rd generation 132 cases, an amoxicillin 42 cases, amoxicillin-clavulanic acid combination 23 cases and a macrolide 34 cases. The mean duration of oral antibiotic therapy was $9.1 \pm 1.8$ days and $7.4 \pm 2.7$ days parenteral.

Antipyretic treatment was associated with 226 cases (95.4\%), oxygen therapy 133 cases (56\%), therapeutic milk 58 cases (24.5\%), erythrocytic pellet 30 cases (12.6\%), Phenobarbital 9 cases (3.8\%) and a hydrolysed electrolyte solute 60 cases $(25.2 \%)$. 
There was a favorable outcome for 179 children (76\%), a complication was observed in 11 children (4\%) with favorable outcome, pleural effusion 8 cases (3\%) and pulmonary emphysema 3 cases (1\%). The mean hospital stay was $6.5 \pm$ 3.2 days ( 1 hour and 23 days). The trend was towards one death in 58 children (24\%).

\section{6) Factors associated with mortality of pneumonia}

The determinants of pneumonia mortality are shown in Table 5 and the factors associated with death in Table 6.

Table 5. Determinants of pneumonia mortality.

\begin{tabular}{|c|c|c|c|c|}
\hline & $\begin{array}{l}\text { Deceased } \\
\text { children } \\
(\mathrm{n}=58)\end{array}$ & $\begin{array}{l}\text { Alive } \\
\text { children } \\
(\mathrm{n}=179)\end{array}$ & RR 95\% [IC] & $P$ \\
\hline \multicolumn{5}{|l|}{ Factors related to the mother } \\
\hline Age of mother $<20$ ans & $6(10.3 \%)$ & $3(1.7 \%)$ & $2.9[1.7-4.9]$ & 0.002 \\
\hline Mother unschooled & $4(6.8 \%)$ & $1(0.5 \%)$ & $3.4[1.7-4.9]$ & 0.003 \\
\hline Low socio-economic level & $48(82.7 \%)$ & $123(68.7 \%)$ & $1.8[0.9-3.4]$ & 0.03 \\
\hline $\begin{array}{l}\text { Factors related to the child } \\
\text { - Living conditions }\end{array}$ & & & & \\
\hline Number of people per room $\geq 2$ & $54(93.1 \%)$ & $147(82.1 \%)$ & $2.4[0.9-6.2]$ & 0.04 \\
\hline $\begin{array}{l}\text { Use of oil lamps } \\
\text { - } \quad \text { Epidemiology }\end{array}$ & $28(65.5 \%)$ & $75(41.9 \%)$ & $2.0[1.2-3.3]$ & 0.001 \\
\hline Age $<24$ months & $28(48.3 \%)$ & $39(21.8 \%)$ & $3.3[2.1-5.1]$ & 0.000 \\
\hline Female & $35(60.3 \%)$ & $69(38.5 \%)$ & $1.9[1.2-3.0]$ & 0.000 \\
\hline Breastfeeding & $33(57.0 \%)$ & $72(40.2 \%)$ & $1.6[1.0-2.6]$ & 0.002 \\
\hline Vaccine Hib absent & $13(22.4 \%)$ & $21(12.0 \%)$ & $1.7[1.0-2.8]$ & 0.04 \\
\hline Vaccine PCV7 absent & $21(36.2 \%)$ & $25(14.0 \%)$ & $2.3[1.7-6.9]$ & 0.000 \\
\hline Sickle Cell & $8(13.8 \%)$ & $5(2.8 \%)$ & $2.7[1.6-4.5]$ & 0.001 \\
\hline $\begin{array}{l}\text { Antibiotic therapy before hospitalization } \\
\text { - Clinic }\end{array}$ & $45(77.6 \%)$ & $60(33.5 \%)$ & $4.2[2.4-7.6]$ & 0.000 \\
\hline Coma & $14(24.1)$ & $14(24.1)$ & $5.3[2.3-12.9]$ & 0.000 \\
\hline Hypothermia & $10(17.2 \%)$ & $1(0.55 \%)$ & $16.7[1.9-146]$ & 0.000 \\
\hline Polypnoea & $55(94.82 \%)$ & $96(53.63 \%)$ & $10.4[3.3-32.3]$ & 0.000 \\
\hline Respiratory distress & $57(98.27 \%)$ & $76(42 \%)$ & $44.5[6.2-316]$ & 0.01 \\
\hline $\mathrm{SpO}_{2}<90 \%$ & $35(60.3 \%)$ & $9(5.02 \%)$ & $6.6[4.4-10.0]$ & 0.01 \\
\hline Severe dehydration & $5(8.6)$ & $1(0.55 \%)$ & $16.7[1.9-146]$ & 0.000 \\
\hline Staphylococcus aureus & $9(15.5 \%)$ & $14(7.8 \%)$ & $2.8[1.2-6.7]$ & 0.01 \\
\hline Positive HIV Serology & $9(15.51 \%)$ & $10(5.58 \%)$ & $2.0[1.2-3.5]$ & 0.01 \\
\hline Duration of hospitalization $\leq 2$ & $38(65.5 \%)$ & $55(30.7 \%)$ & $2.9[1.8-4.7]$ & 0.000 \\
\hline
\end{tabular}


Table 6. Factors associated with pneumonia mortality.

\begin{tabular}{ccccc}
\hline & Deceased children & Alive children & $\mathbf{R R} *(95 \%$ IC) & $P$ \\
\hline Respiratory distress & $57(98.27 \%)$ & $76(42 \%)$ & $31.2[5.1-245]$ & 0.000 \\
Hypothermia & $10(17.2 \%)$ & $1(0.5 \%)$ & $33.4[3.7-278.3]$ & 0.000 \\
$\mathrm{SpO}_{2}<90 \%$ & $35(60.3 \%)$ & $9(5.02 \%)$ & $4.2[2.1-7.8]$ & 0.000 \\
\hline
\end{tabular}

RR: relative risk; IC: confidence interval; $\mathrm{RR}^{*}=$ adjusted $\mathrm{RR}$.

\section{Discussion}

The study of the pneumonia of children under 5 years in Brazzaville shows that these are frequent: $12.3 \%$ of the hospitalizations and third cause of hospitalization. They are observed in children vaccinated against pneumococcus $80.6 \%$ and Haemophilus influenzae $85.6 \%$. Wasting is noted in $15.6 \%$, and severe wasting in $8.9 \%$. HIV serology is positive in $8 \%$.

When the blood culture is positive, Streptococcus Pneumoniae and Staphylococcus Aureus are the main germs. Very severe pneumonia is more common in infants younger than 24 months $(\mathrm{n}=39(88.6 \%) ; P=0.03)$. The evolution is severe: $24 \%$ of deaths. Factors associated with death from pneumonia include respiratory distress, hypothermia and oxygen saturation below $90 \%$.

\section{1) Epidemiological Data}

The incidence of pneumonia was estimated at $12.3 \%$ in this study. However, it was not possible to compare this frequency because of the absence of the prior known incidence of pneumonia in the Congo and the absence of an epidemiological surveillance system for respiratory diseases. However, the EDS-Congo, 2012 [15] reports a 5\% prevalence of ARI among children under 5 years of age. In the Gambia [16], the incidence of pneumonia is $280 \%$.

The mean age of onset of pneumonia, which varies according to authors [3] [5] [6] [7] [16] [17] [18] [19], is between 11.7 and 19.7 months. The common denominator concerning age is that it is within 24 months [6] [7] [8]. The high prevalence of pneumonia in children under 24 months of age is explained by the immaturity of the immune system of the first two years of life.

The masculine predominance found in this work is a known fact [3] [5] [6] [7] [17] [18] [19] [20]. However, in-depth studies would be needed to identify the determinants of this.

\section{2) Diagnosis of Pneumonia}

The signs suggestive of pneumonia, classical [10], are as noted in this work: fever, crackling rales, respiratory discomfort and cough. But it is known that the absence of cough does not exclude the diagnosis of pneumonia.

Chest radiography is the essential tool for the diagnosis of pneumonia. However, a normal X-ray does not exclude the latter [21] [22], as reported in Central African Republic by Demers et al. [23], where only $41 \%$ of children had a pathological radiograph and 53\% in South Africa According to Vérani et al. [24]. In this work, $3.8 \%$ of children had a normal X-ray. It is here that the WHO criteria become important in resource-limited countries and/or there is a high morbidity 
and mortality associated with pneumonia because they allow pneumonia to be confirmed before radiological imaging, and therefore, to make an early diagnosis [10]. When pneumonia has a radiological translation, it is dominated by alveolar syndrome [13] [24] [25] [26].

The isolation of the germ is not always easy, the blood cultures being rarely positive [5] [7] [18] [19] [27]. However, when the germ is identified, Streptococcus pneumoniae is the most recovered germ [5] [7] [18] [19] [27].

The prevalence of Streptococcus pneumoniae raises the problem of the efficacy of immunization coverage in Brazzaville, as $80.6 \%$ of the children in our series were immunized. Although it has not been possible to determine the serotypes of isolated pneumococci, these results should prompt the Expanded Program on Immunization to be vigilant or even conduct a seroprevalence survey.

The paradox described above is not new since Kuti et al. in the Gambia, before us, had reported a predominance of Streptococcus pneumoniae whereas the vaccination coverage in their case was of the order of $81.9 \%$ [5].

\section{3) Clinical Forms}

The severity profile of pneumonia according to the WHO classification is not unequivocal, as most authors have chosen the study of severe forms [6] [7] [18] [19] [20] [27] [28] [29] [30]. This is similar to the results reported by Sigauque et al. in Mozambique (16\%) [27] (18.5\%), which is twice as high as reported by Bjornstad et al. in Malawi (7.8\%) [29]. Other authors report higher frequencies of very severe forms of pneumonia [7] [8]. These very severe forms are more frequently observed in infants less than 24 months [30] [31] [32].

The disparity in the severity profile of pneumonia is explained by the vaccine status of the study subjects, their nutritional status, the existence or absence of HIV seropositivity or antibiotic self-medication [5] [6] [7] [32] [33]. A not inconsiderable proportion of the children in our series had these favorable factors: 19.4\% were not vaccinated against pneumococcus, $14.4 \%$ against Haemophilus influenzae b, $24.4 \%$ were emaciated or severely emaciated, and $8 \%$ Had HIV positive serology.

Regarding HIV infection, Oko et al. in Brazzaville, claim that pneumonia of the child of less than 12 months is one of the revealing modes of it [33].

\section{4) Evolution}

The mortality rate observed in our series (24\%) is high. Demers et al. in the Central African Republic (13.9\%), Fakunlé et al. in Nigeria (13.9\%), Kuti et al. in Gambia (3.5\%) and Tiewsoh et al. in India (10.4\%) [18] report lower rates. The factors cited upstream, justifying the severe forms of pneumonia can explain this heavy mortality.

In this study, $65.5 \%$ of children had died within the first 48 hours and the risk of death during this time was 2.9 times greater than that. Tiewsoh et al. in India [18] as well as Oko et al. [33] in Brazzaville had before us made the same observation.

5) Determinants and factors associated with mortality 
The sociodemographic determinants of pneumonia mortality are: the young age of the mother $[\mathrm{RR}=2.9$; CI $1.7-4.9]$ and Unschooled $[\mathrm{RR}=3.4$; CI 1.7 4.9], and the low socio-economic level of the family [RR $=1.8$; IC $0.9-3.4]$. In Gambia, Kuti et al. [6] report results similar to ours in terms of socio-economic level; In Brazil, De Fonseca Lima et al. [34], with regard to the young age of the mother and her low level of education, which according to these authors put children twice as likely to die from pneumonia. In Brazil, Nascimento et al. explain these results by the immaturity of mothers and their unpreparedness to take care of a child [35].

WHO [36] reports that the infant and child mortality rate is 104 per thousand for low-income families, while families with a high socio-economic status have a mortality rate of 62 per thousand. Similarly, the mother's level of education has a direct influence on the infant mortality rate. A child whose mother has no education is 1.5 times more likely to die before the age of 5 than the mother whose education is at least secondary. Jroundi and Demers [19] [23] note no link between socio-demographic characteristics and death.

The protective role of exclusive breastfeeding already reported [37] [38], thus reinforces the WHO recommendation for the practice of exclusive breastfeeding for up to 6 months [36].

The environmental determinants of mortality are as in the works of Fakunle, Cardoso and Shah [17] [38] [39]: the promiscuity and use of the oil lamp.

For promiscuity, the risk of mortality is high when the child shares the room with at least two other people. In India, Shah et al. [39] report that occupying a room by more than two people increases the risk of dying from pneumonia by 1.8 times. This result is not to be used for comparison in other studies. Indeed, the notion of promiscuity is to be relativized since it depends not only on the number of people who occupy a room but also on the dimensions of it and of what it contains.

Regarding the use of oil lamps in India, Sharma et al. report that they would increase the risk of mortality from pneumonia by 4.1 times [40]. These authors explain that petroleum lamps are potential sources of particularly harmful substances such as polycyclic aromatic hydrocarbons, aliphatic hydrocarbons and hydrocarbon nitrates that are inhaled deeply into the lungs [41].

The risk factors for mortality identified are those described in the literature: respiratory distress $[\mathrm{RR}=31.2$; IC 5.1 - 245], hypothermia $[\mathrm{RR}=33.4$; IC 3.7 278.3] and hypoxemia [RR = 4.2; IC $2.1-7.8$ ] [19] [29] [31].

\section{Conclusion}

This study of 237 children under five hospitalized for pneumonia shows a frequency of $12.3 \%$, the third cause of hospitalization. Children aged 1 to 24 months are the most affected. The germs identified were Streptococcus pneumoniae 42 cases (17.5\%), Staphylococcus aureus 23 cases (9.6\%) and Klebsiella pneumoniae 9 cases $(3.7 \%)$. Factors associated with death for pneumonia are: 
respiratory distress, hypothermia and hypoxemia.

\section{Conflicts of Interest}

Authors do not declare any conflicts of interest.

\section{References}

[1] WHO (2013) Ending Preventable Deaths of Children by Pneumonia and Diarrhea by 2015: Integrated Action Plan to Prevent and Combat Pneumonia and Diarrhea. Geneva, 72 p. Available at: http://www.who.int/iris/bitstream/10665/95480/1/9789242505238_free.pdf

[2] Sectish, T.C. and Prober, C.G. (2004) Pneumonia. In: Behrman, R.E., Kliegman, R.M., Jensen, H.B., Eds., Nelson. Textbook of Pediatrics. 17th Edition, WB Saunders, Philadelphia, 1432-1436.

[3] Rudan, I., Tomaskovic, L., Boschi-Pinto, C. and Campbell, H. (2004) WHO Child Health Epidemiology Reference Group. Global Estimate of the Incidence of Clinical Pneumonia among Children under Five Years of Age. Bull WHO, 82, 895-903.

[4] UNICEF-WHO (2015) Countdown to 2015: A Decade of Tracking Progress for Maternal, Newborn and Child Survival. The 2015 Report, WHO-UNICEF, Geneva, New York.

[5] Kuti, B.P., Ademola Adegoke, S., Ese Ebruke, B., Howie, S., et al. (2013) Risk Factors for Mortality in Childhood Pneumonia in a Rural West African Region. Pediatric Infectious Disease Journal, 8, 131-138.

[6] Nantanda, R., Hildenwall, H., Peterson, S., Kaddu-Mulindwa, D., Kalyesubula, I. and Tumwine, K. (2008) Bacterial Aetiology and Outcome in Children with Severe Pneumonia in Uganda. Annals of Tropical Paediatrics, 28, 253-260. https://doi.org/10.1179/146532808X375404

[7] Webb, C., Mwanajuma Ngama, M., Ngatia, A., et al. (2012) Traitement Failure among Kenyan Children with Severe Pneumonia. A Cohort Study. Pediatric Infectious Disease Journal, 31, e152-e157. https://doi.org/10.1097/INF.0b013e3182638012

[8] Amon Tanoh Dick, F., Domoua, K., N'GouanDomoua, A.M. and Msellati, P. (1998) Etiologies of Pulmonary Complications of Pediatric AIDS in Sub-Saharan Africa. Médecine et Maladies Infectieuses, 28, 428-432. https://doi.org/10.1016/S0399-077X(98)80124-8

[9] Moyen, G., Dinga, H., Mbika-Cardorelle, A. and Okoko, A.R. (2004) Urgences Médicales en Réanimation Pédiatrique. Médecine d'Afrique Noire, 51, 665-669.

[10] WHO (2005) Pocket Book of Hospital Care for Children: Guideline for the Management of Common Illnesses with Limited Resources. World health Organisation, Geneva.

[11] Ministry of Planning (2006) Regional Planning and Economic Integration. Congolese Household Survey for Poverty Assessment. http://www.cnsee.org

[12] WHO Multicenter Growth Reference Study Group (2006) WHO Child Growth Standards: Length/Height-for-Age, Weight-for-A, Weigth-for-Length, Weigth-for-Heigth and Body Mass Index-for Age: Methods and Development. WHO, Geneva.

[13] Cherian, T., Kim Mulholland, E., Carlin, J.B., Ostensen, H., Amin, R., et al. (2005) Standardized Interpretation of Paediatric Chest Radiographs for the Diagnosis of Pneumonia in Epidemiological Studies. Bulletin of the World Health Organization, 83, 353-359. 
[14] WHO (2010) Antiretroviral Treatment of HIV Infection in Infants and Children: Towards Universal Access.

http://www.who.int/hiv/topics/paediatrics/en/index.html, consulted 15 november 2016.

[15] Demographic and Health Survey, Congo, 2012. http://www.cnsee.org

[16] Enwere, G., Cheung, Y.B., Zaman, S.M.A., Akano, A., et al. (2007) Epidemiology and Clinical Features of Pneumonia According to Radiographic Findings in Gambian Children. Tropical Medicine \& International Health, 12, 1377-1385. https://doi.org/10.1111/j.1365-3156.2007.01922.x

[17] Fakunle, G.A., Ana, G.R. and Ayede, A.I. (2014) Environmental Risk Factors for Acute Respiratory Infections in Hospitalized Children under 5 Years of Age in Ibadan, Nigeria. Paediatrics and Child Health, 34, 120-124. https://doi.org/10.1179/2046905513Y.0000000107

[18] Tiewsoh, K., Lodha, R., Pandey, R.M., Broor, S., Kalaivani, M. and Kabra, S.K. (2009) Factors Determining the Outcome of Children Hospitalized with Severe Pneumonia. BMC Pediatrics, 9, 15. https://doi.org/10.1186/1471-2431-9-15

[19] Jroundi, I., Mahraoui, C., Benmessaoud, R., Moraleda, C., et al. (2014) Risk Factors of a Poor Outcome among Children Admitted with Clinically Severe Pneumonia to a University Hospital in Rabat, Morocco. International Journal of Infectious Diseases, 28, 164-170. https://doi.org/10.1016/j.ijid.2014.07.027

[20] Le Roux, D.M., Myer, L., Nicol, M.P. and Zar, H.J. (2015) Incidence and Severity of Childhood Pneumonia in First Year of Life in a South African Birth Cohort: Drakenstein Child Health Study. The Lancet Global Health, 3, e95-e103. https://doi.org/10.1016/S2214-109X(14)70360-2

[21] Lynch, T., Platt, R., Gouin, S., Larson, C., et al. (2004) Can We Predict Which Children with Clinically Suspected Pneumonia We Have the Presence of Focal Infiltates on Chest Radiographs? Pediatrics, 113, 186-189. https://doi.org/10.1542/peds.113.3.e186

[22] Obaro, S. and Madhi, S.A. (2006) Bacterial Pneumonia Vaccines and Childhood Pneumonia, Are We Winning, Refining or Redefining? The Lancet Infectious Diseases, 6, 150-161. https://doi.org/10.1016/S1473-3099(06)70411-X

[23] Demers, A.M., Morency, P., Mberyo-Yaah, F., Jaffar, S., Blais, C., et al. (2000) Risk Factors for Mortality among Children Hospitalized Because of Acute Respiratory Infections in Bangui, Central African Republic. The Pediatric Infectious Disease Journal, 19, 424-432. https://doi.org/10.1097/00006454-200005000-00007

[24] Verani, J.R., Groome, M.J., et al. (2016) Risk Factors for Presumed Bacterial Pneumonia among HIV-Uninfected Children Hospitalized in Soweto, South Africa. The Pediatric Infectious Disease Journal, 35, 1169-1174. https://doi.org/10.1097/INF.0000000000001264

[25] Nagoran, K., Nagoan-Domoua, A.M., Alihonou, S. and Konan, A.N. (2012) Les pneumopathies aigues du nourrisson en Côte d'Ivoire: Apport de la radiographie thoracique dans la recherche étiologique et la prise en charge précoce. The Pan African Medical Journal, 13, 11.

[26] Sylla, M., Kone, A., Diakité, A.A., Maiga, B., Toure, A. and Sidibé, T. (2014) Causes virales et bactériennes des pneumonies chez les enfants de moins de 5 ans à Bamako. Archives de Pédiatrie, 21, 808. https://doi.org/10.1016/S0929-693X(14)72068-8

[27] Sigauque, B., Rocca, A., Bassat, Q., Quinto, L., Berenguera, A., et al. (2016) Severe Pneumonia in Mozambican Young Children: Clinical and Radiological Characteris- 
tics and Risk Factors. Journal of Tropical Pediatrics, 55, 379-387. https://doi.org/10.1093/tropej/fmp030

[28] Jroundi, I., Mahraoui, C., Benmesaoud, R., Moraleda, C., et al. (2013) Antibiotic Usage Prior and during Hospitalization for Clinical Severe Pneumonia in Children under Five Years of Age in Rabat, Morocco. Antibiotics, 2, 450-464. https://doi.org/10.3390/antibiotics2040450

[29] Bjornstad, E., Preidis, G.A., Lufesi, N., Olson, D., Kamthunzi, P., et al. (2014) Determining the Quality of IMCI Pneumonia Care in Malawian Children. Paediatr Internat Child Health, 34, 29-36. https://doi.org/10.1179/2046905513Y.0000000070

[30] Enarson, P.M., Gie, R.P., Mwansambo, C.C., Chalira, A.E., Lufesi, N.N., Maganga, E.R., et al. (2015) Potencially Modifiable Factors Associated with Death of Infants and Children with Severe Pneumonia Routinely Managed in District Hospitals in Malawi. PIoS ONE, 10, e0133365. https://doi.org/10.1371/journal.pone.0133365

[31] McCullers, J.A. (2006) Insights into the Interaction between Influenza Virus and Pneumococcus. Clinical Microbiology Reviews, 19, 571-582. https://doi.org/10.1128/CMR.00058-05

[32] Shann, F., Hart, K. and Thomas, D. (1984) Acute Lower Respiratory Tract Infections in Children: Possible Criteria for Selection of Patients for Antibiotic Therapy and Hospital Admission. Bulletin of the World Health Organization, 62, 749-753.

[33] Oko, A.P.G., Okoko, A.R., Moyen, E. and Moyen, G. (2012) Impact de l'infection à $\mathrm{VIH}$ dans les pneumopathies du nourrisson à Brazzaville. Medecine d'Afrique Noire, 59, 557-562.

[34] Fonseca Lima, E.J., Mello, M.J., Albuquerque, et al. (2016) Risk Factors for Community-Acquired Pneumonia in Children under Five Years of Age in the Post-Pneumococcal Conjugate Vaccine Era in Brazil: A Case Control Study. BMC Pediatric, 16, 157. https://doi.org/10.1186/s12887-016-0695-6

[35] Nascimento, L.F., Marcitelli, R., Agostinho, F.S., et al. (2004) Hierarchical Aproach to Determining Risks factors for Pneumonia in Children. Jornal Brasileiro de Pneumologia, 30, 445-451. https://doi.org/10.1590/S1806-37132004000500008

[36] Objectifsdu Millenaire pour le developpement. https://www.afdb.org/fr/topics-and-sectors/topics/millennium-development-goalsmdgs/

[37] Yoon, P.W., Black, R.E., Moulton, L.H., et al. (1996) Effect of Not Breastfeeding on the Risk of Diarrhoea and Respiratory Mortality in Children under 2 Years of Age in Metro Cebu, Phillipines. American Journal of Epidemiology, 143, 1142-1148. https://doi.org/10.1093/oxfordjournals.aje.a008692

[38] Cardoso, M.R., Cousens, S.N., et al. (2004) Risks Factors or Protectives Factors for Lower Respiratory Disease in Young Children? BMC Public Health, 4, 19. https://doi.org/10.1186/1471-2458-4-19

[39] Shah, N., Ramankutty, V., Premilia, P.G., et al. (1994) Risk Factor for Severe Pneumonia in Children in South Kerala: A Hospital-Based Case-Control Study. Journal of Tropical Pediatrics, 40, 201-216. https://doi.org/10.1093/tropej/40.4.201

[40] Sharma, S., Sethi, G.R. and Rohtagi, A. (1998) Indoor Air Quality and Acute Lower Respiratory Infectious in Indian Urban Seums. Environmental Health Perspectives, 106, 291-297. https://doi.org/10.1289/ehp.98106291

[41] Smith, K., Samet, J., Romien, J., et al. (2000) Indoor Air Pollution in Developing Countries and Acute Respiratory Infectious in Children. Thorax, 55, 518-532.

https://doi.org/10.1136/thorax.55.6.518 
Submit or recommend next manuscript to SCIRP and we will provide best service for you:

Accepting pre-submission inquiries through Email, Facebook, LinkedIn, Twitter, etc. A wide selection of journals (inclusive of 9 subjects, more than 200 journals)

Providing 24-hour high-quality service

User-friendly online submission system

Fair and swift peer-review system

Efficient typesetting and proofreading procedure

Display of the result of downloads and visits, as well as the number of cited articles Maximum dissemination of your research work

Submit your manuscript at: http://papersubmission.scirp.org/

Or contact ojped@scirp.org 